\title{
PSEUDO-STATIC EXPERIMENT AND ANALYSIS ON SEISMIC BEHAVIOR OF THE RC COLUMNS STRENGTHENED BY GHPFRCC
}

\author{
Xiuling $\mathbf{L i}^{\mathrm{a}}$, \\ Juan Wang ${ }^{\mathrm{a}}$, \\ Min Luo, \\ a) School of Civil Engineering, Shandong Jianzhu University \\ Jinan Shandong, China \\ b) Sichuan Engineering Technical College \\ Deyang Sichuan, China
}

\begin{abstract}
Green high performance fiber reinforced cementitious composites (GHPFRCC) are a new class of sustainable cementitious composites, employing a high volume of fly ash to replace cement. In addition to increasing the sustainability of the construction environment, GHPFRCC exhibits a high tensile ductility and multiple cracking behaviors in the strainhardening state. These materials can effectively improve the structural energy dissipation capacity and structural durability. In this study, the optimum mixture ratio of GHPFRCC is presented established using an orthogonal experiment for a specific engineering application. The described GHPFRCC sustains the mechanical performance of concrete and is employed as the outer cladding to strengthen concrete columns. The finite element analysis of the material was based on the software ABAQUS and pseudo static experiments were conducted to exhibit retrofitting of GHPFRCC applied in the rehabilitation of seismic-damaged concrete columns. The computed and experimental results showed that GHPFRCC, while incorporating high volume fly ash, can retain significant multiple cracking behaviors. The energy dissipation capacity of the GHPFRCC reinforced concrete (RC) column is better than the comparable unreinforced column.
\end{abstract}

Keywords: Green high performance fiber reinforced cementitious composites (GHPFRCC), pseudo-static test, reinforced concrete (RC) column, strengthen, seismic performance

\section{INTRODUCTION}

Global earthquake disasters have occurred with increasing frequency in recent years, such as Wenchuan earthquake in China, which caused great casualties and property losses [2]. The seismic damage of reinforced concrete frame columns during an earthquake may cause fatal impact to the structure. To avoid the collapse of a frame structure during an earthquake, improving the seismic performance of the frame column is crucial. Methods for effectively strengthening earthquakedamaged reinforced concrete (RC) columns have become an important problem in the civil engineering field $[8,9]$.

A promising approach for improving the seismic performance of concrete columns is to employ concrete materials utilizing reinforcing materials such as steel fibers [13], carbon fiber reinforced polymers (CFRP) $[1,15]$, etc. Among these, green high performance fiber reinforced cementitious composites (GHPFRCC) are a new type of environment-friendly of cement-based composites with attractive characteristics for use in civil applications. These new materials exhibit including extremely remarkable pseudo strain hardening behavior, saturated multiple cracking, ultra-high toughness, and are environmentally sustainable [3, 7]. Therefore, GHPFRCC is becoming a preferable repair material to strengthen the mechanical performance of reinforced concrete structures.

In this study, we intended to test the feasibility of seismic damaged concrete columns strengthened by GHPFRCC using a computer simulation and laboratory experiments, the aim of which is to provide a solution to the problem of retrofitting earthquake-damaged concrete strictures. The optimum mixing ratio of the GHPFRCC was designed using an orthogonal experiment method and two columns were strengthened by enwrapping different thickness of this designed GHPFRCC [6]. The finite element models of the two retrofitted columns and the unwrapped column were fabricated built and the P- $\Delta$ curves were calculated. Finally, laboratory experiments on the three specimens were conducted using a low frequency cyclic load. Both the calculations and experiment results indicated that GHPFRCC is effective in increasing the seismic energy dissipation capacity of the RC columns. 


\section{MATERIAL PARAMETERS OF GHPFRCC}

The GHPFRCC material is comprised of water, fine sand, polyvinyl alcohol (PVA) fibers, cement, fly ash and a water reducing agent. And the mechanical properties of these materials are as follows [5].

The mesh number of the fine sand (from Qingdao) was 106-180 and the effective particle size was $151 \mu \mathrm{m}$, the density was $2660 \mathrm{~kg} / \mathrm{m}^{3}$, crashed-rate was 0.34 , wear rate 0.40 , silt content 0.06 , solubility in hydrochloric acid 0.24 , content of $\mathrm{SO} 2 \leq 98.96 \%$.

PVA fibers (Kuraray Co. Ltd., Rec15, Japan) were used as the reinforcing fibers in GHPFRCC. The mechanical and geometrical properties were as follows: length $12 \mathrm{~mm}$, diameter $39 \mu \mathrm{m}$, tensile strength $1620 \mathrm{MPa}$, elongation 7\%, Young's modulus $42.8 \mathrm{GPa}$, and density $1.3 \mathrm{~g} / \mathrm{mm} 3$.

Ordinary Portland cement (type P.O. 42.5 R, Shandong Shanshui Cement Group Ltd.) was used and the density was $3100 \mathrm{~kg} / \mathrm{m} 3$; initial setting time was 170 mins, final setting time was $200 \mathrm{mins}$, the specific surface area was $350 \mathrm{~kg} / \mathrm{m} 2$, the content of $\mathrm{SO} 3 \leq 2 \%$, content of $\mathrm{MgO} \leq 4.5 \%$, the compressive and flexural strength of the $28 \mathrm{~d}$ cure of the concrete was 51 $\mathrm{MPa}$ and 9.5 $\mathrm{MPa}$, respectively.

The density of the fly ash (Grade I, Shandong Zoucheng Power Plant) was $2200 \mathrm{~kg} / \mathrm{m} 3$, and the water demand was $91 \%$, material loss on ignition was $2.8 \%$, moisture content $\leq 2 \%$, the amount retained on a $45 \mu \mathrm{m}$ sieve was $9 \%$.

The water reducing agent was obtained from the Shandong Huadi Construction Technology Company. It was a polycarboxylate water reducing agent and its solid content was $25 \%$, Alkali content $0.01 \%$, the $\mathrm{pH}$ value of the material 7.0 .

Tap water was used throughout the study.

In previous studies, the mechanical properties of GHPFRCC such as compressive strength, tensile stress-strain, bending strength-deflection were analyzed with respect to variations in mixing ratios and the optimal value was determined [10], shown as Tab. 1. The mechanics performance results of GHPFRCC with this optimum mixture ratio are shown in Tab. 2.

Tab. 1. Optimum mixture of the GHPFRCC

\begin{tabular}{c|c|c|c|c}
\hline Water Binder Ratio & Sand Binder Ratio & PVA Fiber/\% & Fly Ash/\% & Water Reducing Agent $/ \%$ \\
\hline 0.24 & 0.46 & 1.70 & 60 & 0.10 \\
\hline
\end{tabular}

Tab. 2. Test results for GHPFRCC with Optimum Mixture Ratio

\begin{tabular}{c|c|c|c|c}
\hline $\begin{array}{c}\text { Compressive } \\
\text { Strength }\end{array}$ & $\begin{array}{c}\text { Tensile } \\
\text { Strength }\end{array}$ & $\begin{array}{c}\text { Bending } \\
\text { Strength }\end{array}$ & $\begin{array}{c}\text { Elasticity } \\
\text { Modulus }\end{array}$ & $\begin{array}{c}\text { Poisson's } \\
\text { Ratio }\end{array}$ \\
\hline $42.15 \mathrm{MPa}$ & $3.02 \mathrm{MPa}$ & $14.5 \mathrm{MPa}$ & $2.91 \times 10^{4} \mathrm{MPa}$ & 0.23 \\
\hline
\end{tabular}

\section{FINITE ELEMENT ANALYSIS BASED ON ABAQUS}

Three concrete columns were used to simulate the seismic performance subjected by the low-frequency cyclic load. Among these sample, column A was a pure C30 concrete control column, column B was wrapped with a $25 \mathrm{~mm}$ thickness of
GHPFRCC, column C was wrapped with a $35 \mathrm{~mm}$ thickness of GHPFRCC and the three columns had the same section size and steel reinforcements. The concrete geometry size and reinforcement diagram are shown in Fig. 1.

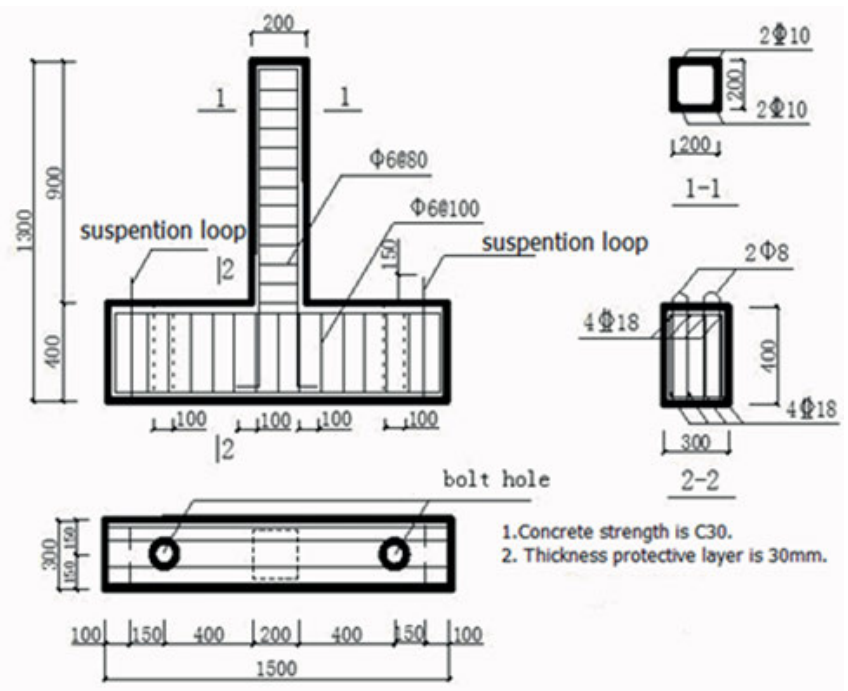

Fig. 1. Reinforced concrete column

The finite element software ABAQUS was used to analyze the seismic behavior of the three columns. Basic assumptions were as follows:

(1) The bond-slip problems between GHPFRCC and concrete were not considered;

(2) The bond-slip problem between steel bar and concrete were not considered;

(3) Rebar was considered as the ideal elastic-plastic material;

(4) The nonlinear material problems of concrete were considered in the simulation analysis.

2.1 Finite element model

ABAQUS provides three concrete constitutive models [14]: concrete smeared cracking, damaged concrete plasticity and concrete cracking model. The damaged concrete plasticity model was selected.

The concrete constitutive relationship was chosen from appendix C of "Code for the design of concrete structures" (GB50010-2010) [12] and the bilinear ideal elastic-plastic model was used for the reinforcements.

GHPFRCC has a tensile strain capacity of up to $6 \%$ and exhibits a pseudo-strain hardening behavior accompanied by multiple cracking. The tensile and compressive constitutive relationship of GHPFRCC is shown as Fig. 2(a), (b), respectively [4].

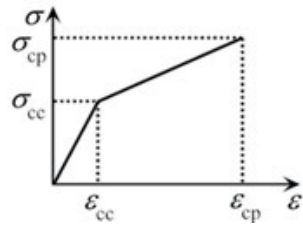

(a) Tensile stress-strain curve

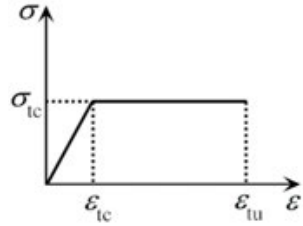

(b) Compressive stress-strain curve
Fig. 2. GHPFRCC constitutive relations 
The compressive stress $\boldsymbol{\sigma}_{c}$ and tensile stress $\boldsymbol{\sigma}_{\mathrm{t}}$ of GHPFRCC can be calculated using Equation (1) and Equation (2).

$$
\begin{gathered}
\sigma_{\mathrm{t}}= \begin{cases}\frac{\varepsilon}{\varepsilon_{\mathrm{tc}}} \sigma_{\mathrm{tc}} & 0<\varepsilon<\varepsilon_{\mathrm{tc}} \\
\sigma_{\mathrm{tc}} & \varepsilon \geq \varepsilon_{\mathrm{tc}}\end{cases} \\
\sigma_{\mathrm{c}}= \begin{cases}\frac{\varepsilon}{\varepsilon_{\mathrm{cc}}} \sigma_{\mathrm{cc}} & 0<\varepsilon \leq \varepsilon_{\mathrm{cc}} \\
\sigma_{\mathrm{cc}}+\frac{\varepsilon-\varepsilon_{\mathrm{cc}}}{\varepsilon_{\mathrm{cp}}-\varepsilon_{\mathrm{cc}}}\left(\sigma_{\mathrm{cp}}-\sigma_{\mathrm{cc}}\right) & \varepsilon_{\mathrm{cc}}<\varepsilon \leq \varepsilon_{\mathrm{cp}}\end{cases}
\end{gathered}
$$

The embedded element was used to simulate the bond between rebar and concrete. GHPFRCC has a favorable bond behavior with concrete and steel reinforcements. The tie connection method was adopted between the concrete and GHPFRCC, as well as between the cushion block and column and the column and transverse beam.

The vertical concentrated force at the top of column was exerted by the Ramp curve of ABAQUS and the force was $120 \mathrm{kN}$ (axial compression ratio is 0.15). The horizontal load was imposed through the set load amplitude curves under displacement control. The six degrees of freedom of the transverse beam at the bottom of column were all restrained, i.e. $\mathrm{U} 1=\mathrm{U} 2=\mathrm{U} 3=\mathrm{UR} 1=\mathrm{UR} 2=\mathrm{UR} 3=0$.

During the mesh generation, the Hex element was adopted for concrete and the GHPFRCC element shape and C3D8R for the element type. T3D2 element was selected for reinforcement.

2.2 Calculated results and analysis

Stress nephograms of the three columns are shown in Fig. 3(a), (b), (c), respectively. The load-displacement skeleton curves obtained from the data processing are shown in Fig. 4(a), (b), (c), respectively.

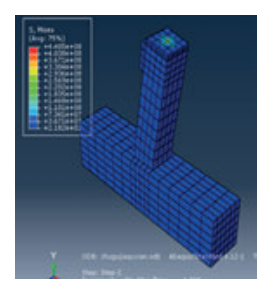

(a) Column A

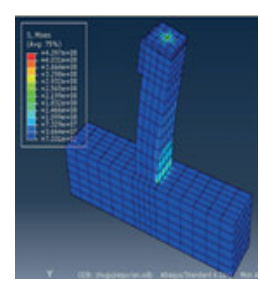

(b) Column B

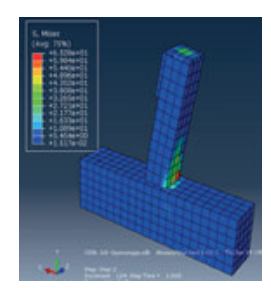

(c) Column C
Fig. 3. Stress nephogram of analysis results

The simulation results show that the maximum horizontally bearing capacity of column A was $76 \mathrm{kN}$, the ultimate displacement was $22 \mathrm{~mm}$; for column $\mathrm{B}$, the maximum bearing capacity was $98.4 \mathrm{kN}$ with a displacement of $53.1 \mathrm{~mm}$, and for column $\mathrm{C}$, the maximum bearing capacity was $101.5 \mathrm{kN}$ with a displacement of $63.4 \mathrm{~mm}$.

As can be seen, reinforced concrete columns strengthened by GHPFRCC have good ductility and energy-absorbing ability and the effects improve with the increase of the wrapped thickness of the GHPFRCC.

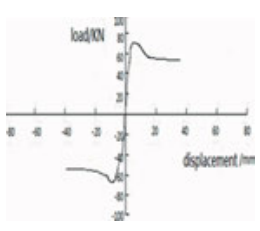

(a) Column A

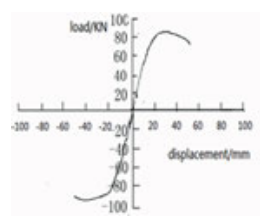

(b) Column B

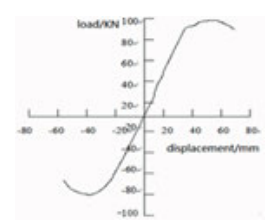

(c) Column C
Fig. 4. P- $\Delta$ skeleton curves of analysis results

\section{EXPERIMENTAL WORK}

Three reinforced concrete columns were considered and the strengthening schemes are shown in Tab. 3. The reinforcement diagram is shown in Fig. 1. HRB400 and HPB300 are chosen for steel reinforcements and stirrups, respectively. The readymixed concrete with grade $\mathrm{C} 30$ was adopted.

Tab. 3. Strengthening Schemes

\begin{tabular}{c|c|c|c|c}
\hline No. & $\begin{array}{c}\text { Height } \\
(\mathrm{mm})\end{array}$ & $\begin{array}{c}\text { Section } \\
\text { size }\left(\mathrm{mm}^{2}\right)\end{array}$ & Strengthening methods & $\begin{array}{c}\text { Section size after } \\
\text { strengthened }\left(\mathrm{mm}^{2}\right)\end{array}$ \\
\hline column A & 900 & $200 \times 200$ & -- & $200 \times 200$ \\
\hline column B & 900 & $150 \times 150$ & Outsourced 25mm thick GHPFRCC & $200 \times 200$ \\
\hline column C & 900 & $130 \times 130$ & Outsourced 35mm thick GHPFRCC & $200 \times 200$ \\
\hline
\end{tabular}

Strain gauges were adhered to the steel reinforcements prior to concrete pouring. The control column A was cast at the same time and column $\mathrm{B}$ and $\mathrm{C}$ adopted secondary casting. Initially columns B and $\mathrm{C}$ were cast according to the size shown in Tab. 3 and then wrapped with different thickness of GHPFRCC after 28 days' of humid preservation curing. The wrapped thickness of GHPFRCC was $25 \mathrm{~mm}$ and $35 \mathrm{~mm}$ for column B and C, respectively. In order to obtain good bonding performance between GHPFRCC and the concrete, it was necessary to polish the concrete surface prior to the second pouring of GHPFRCC.

The pseudo-static experiment was conducted with the MTS system. In order to observe the experimental phenomenon more clearly, the concrete column surface was whitewashed with $5 \mathrm{~cm} \times 5 \mathrm{~cm}$ grids before the test. To ensure a smooth surface, a layer of mortar was cast on top of the column.

Displacement at top of column was measured using a laser range finder and strain was recorded using the Shanghai Zhubang Cekong system. The hysteresis curve was automatically extracted from the MTS. The loading process controlled by the sample deformation and the initial deformation step was $1 \mathrm{~mm}$ with $1 \mathrm{~mm}$ deformation increments, and the system was cycled twice for each deformation magnitude (see Fig. 5).

When the bearing capacity dropped to $85 \%$ of the maximum load and not less than the yield load, the columns would fail and the test would be terminated [3]. The experimental apparatus is shown Fig. 6 . 


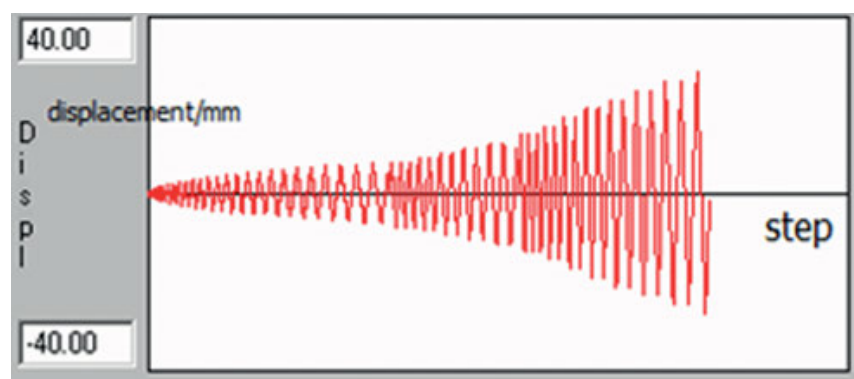

Fig. 5. Loading system

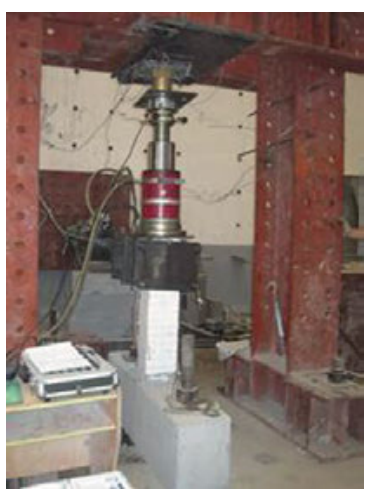

Fig. 6. Test apparatus

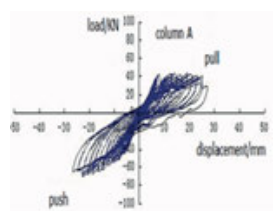

(a) column A

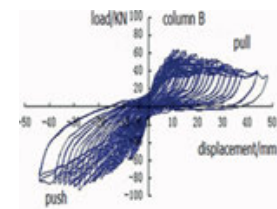

(b) column B

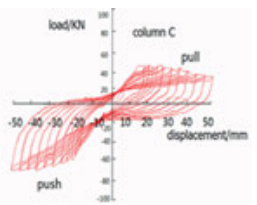

(c) column C
Fig. 7. Hysteresis curves of test results

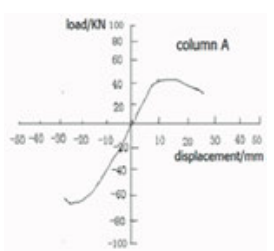

(a) column $\mathrm{A}$

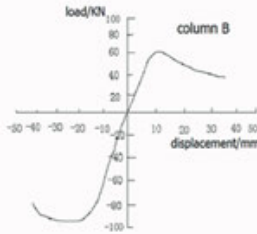

(b) column B

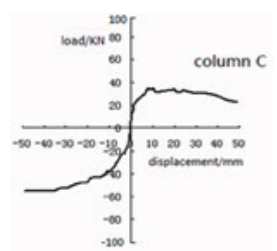

(c) column C
Fig. 8. P- $\Delta$ skeleton curves of test results

\section{RESULTS AND DISCUSSION}

Columns A, B, C were tested using a low frequency cyclic loading test and the load-deformation hysteresis curves collected by the MTS are shown in Fig. 7. The P- $\Delta$ skeleton curves were obtained by connecting the hysteresis curve peak at each loading level the first cycle (see Fig. 8).

For the control column A, the bearing load increases slightly after cracks appeared at the bottom side of the column. With the increase of the controlled deformation, the concrete at the bottom of column began to be crushed and the maximum crack width reached $5 \mathrm{~mm}$. The appearance of two main penetrating cracks at the bottom of the column leads to the failure of column A. For column B, wrapped with $25 \mathrm{~mm}$ of GHPFRCC, there are no main penetrating cracks, but many transverse fine cracks and the maximum crack width was less than $0.1 \mathrm{~mm}$. For column C, wrapped with $35 \mathrm{~mm}$ of GHPFRCC, there are fewer cracks than column B, but the cracks appeared early at the bottom of the column and the GHPFRCC detached from the crossbeam.

In terms of bearing capacity, the maximum load of column A was $69.19 \mathrm{kN}$, and the maximum value of column B was 92.06 $\mathrm{kN}$, which increased by approximately $31 \%$ in comparison to the control column A.

The maximum displacement of column A, B and C was $26 \mathrm{~mm}, 46 \mathrm{~mm}$, and $49 \mathrm{~mm}$, respectively.

The surrounding area of the hysteresis curve of the columns strengthened by GHPFRCC was larger than the control column and it means that the energy dissipation capability improved. Even at the plastic stage, the GHPFRCC can still absorb large amounts of energy after steel reinforcements yield and this demonstrated good ductility.

As can be seen from Fig. 7 and Fig. 8, the load, unload forces of the three columns are not symmetric (generally the load is greater than the unload), the main reasons are as follows. The construction of the material may be subpar leading to a deviation between the specimen and the base of the test system. It was difficult to adjust the height of MTS actuator to be the same as that of the column, so that the actuator is not completely level, resulting in the deviation between load and unload.

\section{CONCLUSIONS}

(1) There was a significant difference between the simulation and experimental results where the test values were less than the simulation values for both sample displacement and ultimate bearing capacity. There was friction between the tackle and the top of the counterforce frame, which influenced the horizontal load which is the main reason for the aforementioned result.

(2) The hysteresis curve of the column strengthened using GHPFRCC is plump, which means that GHPFRCC can effectively improve the bearing capacity and deformation capacity of column, but work is need to improve the retrofitting construction technology.

(3) Strain at the column surface before and after reinforcement is nearly the same and the deformation between GHPFRCC and concrete is coordinated.

\section{ACKNOWLEDGEMENT}

This work was financially supported by the National Natural Science Foundation of China (Grant Nos. 51278290 and 51108253), the Science and Technology Planning Project of Housing and Urban-Rural Development Ministry (Grant No. 2012-K2-11), Program for Scientific Research Innovation Team in Colleges and Universities of Shandong Province, and Educational Commission of Shandong Province (Grant No. J11LE09), and the Ministry of Education Innovation Team (Grant No. IRT13075). 


\section{REFERENCES}

1. Haddad, R. H., AL-Mekhlafy, N., and Ashteyat, A. M., Repair of heat-damaged reinforced concrete slabs using fibrous composite materials, Construction and Building Materials, Vol. 25, no. 3, pp. 1213-1221, 2011.

2. Li, H. N., Li, X. L., Experiment and analysis of torsional seismic responses for asymmetric structures with semiactive control by MR dampers, Smart Materials and Structures, Vol. 18, no. 7, pp. 1-10, 2009.

3. Li, V. C., Tailoring ECC for Special Attributes: A Review, International Journal of Concrete Structures and Materials, Vol. 6, no. 3, pp. 135-144, 2011.

4. Li, X. L., Luo, M., Study on the reinforced concrete column strengthened by GHPFRCC with high volume of fly ash, Applied Mechanics and Materials, Vols.99-100, pp. 213219, 2011.

5. Li, X. L., Luo, M., and Wang, J., Experimental research on the flexural toughness of green high performance fiber reinforced cementitious composites (GHPFRCC), Materials Research Innovations, Vol. 18, no. S2, pp. 43-47, 2014.

6. Li, X. L., Luo, M., and Wang, J., Orthogonal design and performance of green high performance fiber reinforced cementitious composites, Concrete, no. 12, pp. 8-13, 2013. (in Chinese)

7. Li, X. L., Wang, J., Compressive Strength and Poisson's Ratio of green high performance fiber reinforced cementitious composites, Concrete, no. 4, pp. 70-73, 2014. (in Chinese)

8. Liang, X. W., Kang, L., Deng, M. K. , and Dang, Z., Experimental investigation on seismic behavior of columns with fiber-reinforced concrete in potential plastic region, Journal of Building Structure, Vol. 35, no. 2, pp. 63-70, 2014. (in Chinese)

9. Lu, Y., Comparative study of seismic behavior of multistory reinforced concrete framed structures, Journal of Structure Engineering, Vol. 128, no. 2, pp. 169-178, 2002

10. Luo, M., Experimental study on the columns reinforced by green high performance fiber reinforced cementitious composites, Jinan: Shandong Jianzhu University, 2013. (in Chinese)

11. Ministry of Construction of the People's Republic of China, JGJ 101-96, Specification of testing methods for earthquake resistant building, Beijing: China Architecture Industry Press, 1997.
12. Ministry of Housing and Urban-Rural Development of the People's Republic of China, GB50010-2010, Code for design of concrete structures, Beijing: China Architecture Industry Press, 2011.

13. Wang, J., Li, H., Chen, X., and Jia, Y. M., Experimental Study on the Seismic Performance of RC Frame with the Steel Fiber RPC Permanent Pillar, Journal of Shenyang Jianzhu University (Natural Science), Vol. 30, no. 2, pp. 220-226, 2014.

14. Wang, Y. Z., Fu, C. G., Structural engineering analysis and example explanation of ABAQUS, Beijing: China building industry press, 2010. (in Chinese)

15. Yu, Y. D., Liu, Y., Zhang, K., and Zheng, Z. K., Study on the ultimate compressive stress of rectangular concrete columns with CFRP sheets under secondary eccentric loading, Journal of Qingdao Technological University, Vol. 35, no. 1, pp. 13-17, 2014. (in Chinese)

\section{CONTACT WITH AUTHOR}

$$
\begin{gathered}
\text { Xiuling Lia } \\
\text { dlutiem@163.com } \\
\text { Juan Wanga }
\end{gathered}
$$

School of Civil Engineering, Shandong Jianzhu University Jinan Shandong, 250101 P. R. China

Tel: 86-0531-86361922, Fax: 86-0531-86361386

Min Luob

Sichuan Engineering Technical College Deyang Sichuan 618000 P. R. China 